\title{
Trabajo docente y políticas de evaluación externa en Colombia y Brasil"
}

Teacher's Work and External Evaluation Policies in Colombia and Brazil

Trabalho docente e políticas de avaliação externa na Colômbia e o Brasil

\section{Juan Francisco Remolina Caviedes** (iD orcid.org/0000-0002-7001-8017}

\section{(9) $(1) \Theta$}

* Este artículo forma parte de la tesis doctoral "Crítica das Políticas de Avaliação Externa na Colômbia e Brasil no contexto da sociedade capitalista", del Doctorado en Educación de la Universidade Federal de Uberlândia, Minas Gerais, en el marco del convenio entre la Organización de Estados Americanos (OEA) y el Grupo Coimbra de Universidades Brasileras (GcuB), el cual ofrece becas a ciudadanos de Estados miembros de la oea para realizar estudios de posgrado en Brasil con financiamiento de la Coordenação de Aperfeiçoamento de Pessoal de Nível Superior (CAPES).

** Doctor en Educación de la Universidade Federal de Uberlândia (Minas Gerais - Brasil), docente Universidad Industrial de Santander, Colombia. Correo electrónico: jfremoca@uis.edu.co 


\section{Resumen}

El presente artículo tiene como objetivo investigar y analizar críticamente en qué medida las políticas de evaluación externa implementadas en Colombia y Brasil influyen en la configuración del trabajo docente. A partir de este interés, nos referimos a las percepciones docentes sobre la materialización de estas políticas en ambas realidades, desde la perspectiva de los estudios históricos comparados en el ámbito de la matriz teórico-metodológica del materialismo histórico-dialéctico. En ese sentido, se realizaron entrevistas semidirigidas a un total de 30 docentes que actuaban en diferentes áreas de seis escuelas públicas de Colombia y Brasil. Los resultados evidenciaron que las políticas educacionales gestadas y diseminadas por organismos multilaterales al servicio del capital, como el Banco Mundial, median en la configuración de las políticas educativas de ambos países por intermedio de la ideología gestiocrática, hecho que contribuye progresivamente a la precarización del trabajo docente.

\section{Palabras clave}

política educacional; calidad de la educación; indicadores educativos; evaluación de la educación; responsabilidad del docente

\section{Keywords}

educational policy; quality of education; educational indicators; evaluation of education; teacher responsibility

\begin{abstract}
This article aims to provide a critical research and analysis of the extent to which the external evaluation policies implemented in Colombia and Brazil influence the configuration of the teacher's work. Based on this interest, we refer to teachers' perceptions about the materialization of these policies in both realities, adopting the perspective of comparative historical studies within the scope of the theoretical-methodological matrix of historical-dialectical materialism. Thus, semi-structured interviews were conducted with a total of 30 teachers who worked in different areas of six public schools in Colombia and Brazil. The results showed that the educational policies developed and disseminated by multilateral organizations in the service of capital, such as the World Bank, mediate in the configuration of the educational policies of both countries through the gestiocratic ideology, contributing progressively to the precarization of teaching work.
\end{abstract}

\begin{abstract}
Resumo
Este artigo visa pesquisar e analisar criticamente em que medida as políticas de avaliação externa implementadas na Colômbia e no Brasil influem na configuração do trabalho docente. A partir disso, abordamos as percepções dos professores sobre a materialização dessas políticas nas duas realidades, desde a perspectiva dos estudos históricos comparados no âmbito da matriz teórico-metodológica do materialismo histórico-dialético. Nesse sentido, realizamos entrevistas semiestruturadas a 30 docentes que trabalhavam em diversas áreas de seis escolas públicas da Colômbia e o Brasil. Os resultados evidenciam que as políticas educacionais criadas e disseminadas por organismos multilaterais ao serviço do capital, como o Banco Mundial, influem na configuração das políticas educacionais dos dois países por meio da ideologia gestocrática, o que contribui progressivamente para a precarização do trabalho docente.
\end{abstract}

\section{Palavras-chave}

política educacional; qualidade da educação; indicadores educacionais; avaliação da educação; responsabilidade do professor 
Estudios comparados han evidenciado que las representaciones sociales de la evaluación escolar parecen desconocer fronteras. Por ejemplo, en la investigación de Remolina (2012), concepciones de autoridad, poder, control, comprensión y mejora del aprendizaje fueron elementos comunes encontrados en la realidad educacional de Francia y Portugal.

Esto demuestra, por un lado, la importancia de los estudios comparados en la tarea de abstraer determinaciones comunes de los fenómenos mediante el análisis de las generalidades y especificidades de contextos particulares. Por otro, Ilama la atención que tales semejanzas se evidencien en realidades tan disimiles y revelen al mismo tiempo el impacto emocional producido por esta práctica educativa sobre los sujetos escolares, entre ellos, el profesorado. Ahora bien, vale la pena preguntar: ¿Por qué este tipo de similitudes? ¿Son acaso la demostración palpable de una dinámica de homogeneización escolar a escala global?

Por otra parte, para De Freitas (2012), desde hace algunos años viene configurándose un proceso de precarización en la formación del profesorado. Una visión pragmática está instalándose en agencias formadoras de docentes, restringiendo tal dinámica a aspectos prácticos de metodologías. Tal es el caso de la ONG Teach for America, que en EE. uU. forma profesores en cinco semanas (Ravitch, 2011).

Además, los procesos de evaluación están individualizando cada vez más al profesorado (De Freitas, 2012). Una política que, en consideración del autor, somete al docente a todo tipo de responsabilidad y de exposición pública, lo que termina socavando el fundamento motivacional de su práctica profesional.

A su vez, no es tema menor que, para organismos internacionales como el Banco Mundial (BM), el trabajo docente resulte íntimamente vinculado con la calidad educativa. En su estudio financiado por el BM, Bruns y Luque (2014) determinaron que la baja calidad del profesorado de América Latina y del Caribe surge como limitante de importante consideración. Su pobre conocimiento de los contenidos y la ineficacia de sus prácticas educativas son factores que, según los autores, comprometen la calidad de la profesión y, en consecuencia, la calidad educacional.

Lo anterior hace pertinente profundizar en reflexiones e investigaciones sobre las políticas de evaluación y sus posibles efectos en la configuración y organización del trabajo docente.

Así, problematizando el objeto de estudio desde el ámbito de la educación colombiana, considero que los Acuerdos de Paz entre el Gobierno colombiano y la guerrilla de las FARC-EP son punto de inflexión en la política educativa del país. Prueba de ello fue la meta fijada por el expresidente Juan Manuel Santos de convertir a Colombia en la nación más educada de América Latina y del Caribe (SIG, 2014); objetivo gubernamental inusitado.

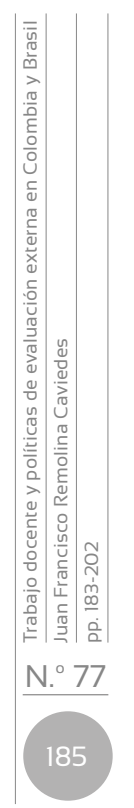


A partir de este contexto es posible observar que tres elementos asumen centralidad en la agenda educacional colombiana: calidad educativa, evaluaciones externas y premios por productividad educacional.

Así, en marzo de 2015, el Ministerio de Educación Nacional (MEN) hace público el nuevo sistema de evaluación inspirado en el modelo brasileño del Estado de Minas Gerais (Malaver, 2015). En ese sentido, se pretende medir la calidad de la enseñanza nacional, mediante un indicador cuantitativo que para su cálculo utiliza los resultados obtenidos por el alumnado en las respectivas pruebas externas nacionales. Este es el caso del índice sintético de calidad educativa (ISCE), una idea basada en el índice de desenvolvimento da educação básica (IDEB) de Brasil (ICFES, 2016).

Ahora bien, el tercer elemento es central en la agenda educacional colombiana, y a su vez, está relacionado con el presente trabajo de investigación: premios a la productividad educativa. Como aconteció en Brasil, específicamente en el Estado de Minas Gerais, el Gobierno colombiano anunció el pago de bonos especiales a docentes que demostraran desempeños positivos en función de los resultados obtenidos por sus estudiantes en pruebas externas (Sánchez, 2015).

Por lo que se pudo observar, el ISCE aparece como articulador entre salario y desempeño docente, esto demuestra una directriz política hasta ahora inédita en el sistema escolar colombiano.

Por esta razón, fue pertinente realizar un estudio comparado entre ambos países, dada la influencia de las políticas de evaluación brasileñas sobre los programas educacionales implementados en Colombia en materia de evaluación, indicadores de calidad y premios a la productividad educativa.

Dada la posibilidad de llevar a cabo un estudio en realidades tan singulares como el contexto escolar colombiano y el brasileño, se ahondó en los principios políticos e ideológicos que sustentaban las evaluaciones externas; se analizaron sus efectos en la organización del trabajo docente en ambos escenarios, y se pusieron de relieve sus idiosincrasias, similitudes y regularidades.

Por tales razones, indagar sobre las ideologías que subyacen a las políticas de evaluación externa fue un ejercicio fundamental para la comprensión de la nueva dinámica que estaría influenciando las condiciones laborales docentes.

En ese sentido, se plantearon dos ejes de investigación: la centralidad de las evaluaciones externas en la configuración de las políticas educacionales de Brasil y Colombia, así como la ideología subyacente a la estructuración de dichas políticas.

En consecuencia, la pregunta que marcó el norte al presente trabajo de investigación fue: ¿De qué manera las políticas de evaluación externa implementadas en Colombia y Brasil influyen en las condiciones laborales del profesorado de ambos países? Por esta razón, el objetivo principal de 
esta pesquisa consistió en analizar críticamente de qué manera las políticas de evaluación externa implementadas en Colombia y Brasil influyen en las condiciones laborales del profesorado de ambos países.

\section{Presupuestos epistemetodológicos}

Para el presente trabajo fueron adoptados tres presupuestos epistemológicos: el materialismo histórico-dialéctico (MHD), la perspectiva de los estudios históricos comparados (EHC) (Franco, 2000; Ciavatta, 2009) y la totalidad concreta (Kosík, 1995).

De tal manera, se implementaron las siete fases del MHD que propone Dussel (2012): 1) lo real concreto (existente); 2) totalidad caótica; 3) determinaciones abstractas; 4) totalidad construida (concreta); 5) categorías explicativas; 6) totalidad concreta histórica explicada, y finalmente, 7) la realidad conocida.

Ahora bien, teniendo en cuenta que los estudios comparados de matiz tradicional toman distancia de los presupuestos epistemológicos asumidos, el presente trabajo asumió el enfoque de los EHC (Franco, 2000; Ciavatta, 2009). Este, además de ser coherente con la postura epistemológica del MHD, también posibilitó la lectura en paralelo de dos realidades distintas. Una mirada que permitió establecer comparaciones entre ambos países a partir de procesos históricos más amplios (comprender la historia como proceso) y propició reconstruir tal visión comparada como parte de una realidad compleja susceptible de transformación (historia como método) (Franco, 2000).

Respecto a nuestro tercer presupuesto epistemológico, asumimos la tridimensionalidad de la totalidad concreta, primero, como respuesta al problema de lo real; segundo, como exigencia metodológica, y finalmente, como postulado epistémico. De tal manera que todos los hechos puedan ser considerados conocimiento de la realidad al ser entendidos como partes estructurales de un todo dialéctico, en el cual o del cual un hecho cualquier (clases de factos, conjunto de factos) puede llegar a ser racionalmente comprendido (Kosík, 1995). Así, sería posible superar la limitación epistemológica del concepto de realidad en cuanto conjunto general de todos los hechos. Por tanto, para el presente trabajo, el análisis crítico de las percepciones docentes podría dar cuenta de la realidad del profesorado y de sus condiciones laborales.

Por tanto, el presente estudio se define a partir de las aproximaciones, los distanciamientos y las contradicciones en las percepciones docentes sobre las políticas de evaluación externa, su lectura y sus ideologías. Por tanto, resultó necesario indicar la forma como fueron interpretadas tales aproximaciones y distanciamientos. 
Cabe resaltar que el presente análisis interpretativo se orientó con la teoría de las representaciones de Lefebvre (2006). La representación es un fenómeno de la conciencia (individual y colectiva) o una cosa o conjunto de cosas. En el primer caso, el fenómeno de la conciencia acompaña una(s) palabra(s) u objeto(s) dentro de una sociedad y lengua determinada. En el segundo caso, como cosa(s), encarna(n) relaciones ya sea para contenerlas o para ocultarlas.

La eficacia de las representaciones, según Lefebvre (2006, p. 68), radica en el hecho de que estas no son falsas ni verdaderas, sino al mismo tiempo falsas y verdaderas. Es decir, "verdaderas como respuestas a problemas 'reales' y falsas como disimuladoras de las finalidades 'reales'". Así, se convierten en el camino intermedio entre instinto e ideología.

En virtud de que el presente trabajo se define a partir de las percepciones docentes, resulta importante definir cómo interpretar el discurso docente.

Para Lefebvre (2006), del mismo modo que con las representaciones, el lenguaje no es verdadero ni falso. Una de sus principales funciones es la disimulación. En consecuencia, para el autor, mensaje y verdad nacen del discurso como lucha por el poder e, igualmente, la lingüística no resulta suficiente en su labor de explicar el sentido del discurso, dado que en este último intervienen otros elementos que producen su sentido, como los valores y las normas socialmente admitidas.

Por consiguiente, aquí se tuvieron en cuenta los valores y las normas establecidas en la sociedad capitalista. Es decir, las representaciones y las ideologías se interpretaron en función de la clase dominante, sin desconsiderar la fuerza de resistencia contraria de quienes las producen. De tal modo, tales manifestaciones fenoménicas fueron admitidas como productos de la lucha de clases. Pero ¿qué concepto de ideología pretendimos asumir?

En primera medida, consideramos que las ideas dominantes de una época, efectivamente, son las ideas de la clase dominante (Marx y Engels, 2014). Por tanto, esto nos permite admitir, como afirmó Lefebvre (1975), que las ideologías son una estrategia consciente de clase, mediante la cual se pretende disimular y ocultar las contradicciones de la realidad, presentándola de manera incompleta.

Se debe agregar que, en el presente trabajo, se tomó el camino de las ideas para llegar al ser humano, de la conciencia al ser (o sea, a la realidad práctica, cotidiana), con el fin de hacer una crítica de las ideas por intermedio de los actos humanos y de la realidad (Lefebvre, 1958). En otras palabras, se llevó acabo una crítica de las políticas de evaluación externa mediante el análisis de las condiciones laborales del trabajador docente colombiano y brasileño. 


\section{Procedimientos metodológicos}

A partir de las anteriores fundamentaciones teórico-metodológicas fueron definidas tres etapas procedimentales: selección institucional y de sujetos docentes, entrevista semidirigida y, finalmente, análisis de datos cualitativos.

En la primera etapa, de selección de las instituciones escolares y de los sujetos docentes, en Brasil, fueron escogidas las siguientes escuelas públicas en la ciudad de Uberlândia (Minas Gerais): Escola Estadual Bueno Brandão, Escola Municipal Mario Godoy, Escola Estadual Lourdes Carvalho. Para el caso de Colombia se trabajó en los siguientes colegios públicos: Colegio Facundo Navas Mantilla de Girón, Instituto Integrado San Bernardo de Floridablanca y Escuela Normal Superior de Bucaramanga.

Respecto al profesorado, en Brasil, fueron entrevistados 13 docentes (7 profesoras y 6 profesores), que actuaban en noveno año de la enseñanza fundamental o tercer año del nivel medio. Mientras en Colombia, se entrevistaron 17 sujetos docentes ( 7 profesoras y 10 profesores), quienes ejercían en grados noveno o undécimo. Los profesionales escogidos tenían a su cargo áreas como Portugués, Español, Filosofía, Matemática, Educación Física, Historia o Ciencias Naturales.

En la segunda etapa, se llevaron a cabo entrevistas semidirigidas utilizando un cuestionario con preguntas de contexto y otras abiertas relacionadas con los ejes centrales de investigación. En Brasil, las entrevistas se efectuaron durante el primer semestre de 2015, mientras que en Colombia, en el segundo semestre del mismo año. De esta manera, se quiso indagar sobre la percepción personal de las evaluaciones externas (objetivos y articulación con la calidad educativa) y sus posibles aspectos ideológicos (influencia de estas evaluaciones en la práctica docente, en la promoción de la competitividad y sus repercusiones emocionales).

En la tercera etapa, correspondiente al análisis crítico de los datos empíricos, cabe resaltar el uso del software Atlas.ti (2015). Dado el procedimiento deductivo-inductivo adoptado, con ayuda de tal herramienta informática, se localizaron categorías a priori para luego llegar a adicionar nuevas categorías (a posteriori), estas últimas también denominadas categorías conceptuales explicativas. Por medio de estas últimas, se pretendió integrar y comprender en una totalidad conceptual construida aquellas determinaciones abstractas más generales, mediante las contradicciones, distanciamientos y aproximaciones encontradas en el discurso docente.

En consecuencia, de esa totalidad conceptual construida, que ofrece sentido a las determinaciones simples y abstractas del discurso docente, aparecieron cuatro categorías conceptuales: a) utilización y circulación de los productos escolares; b) influencia mercadológica de la educación 
y de las políticas de evaluación externa; c) capitalización del cotidiano escolar y, finalmente, d) trabajo docente. Esta última, tema central del presente artículo, cuyo análisis de resultado aparece en la sección "Condiciones laborales en el ámbito de las políticas de evaluación externa" del presente artículo.

Finalmente, siendo coherentes con los postulados metodológicos adoptados, a continuación serán expuestas de manera sintética las ideas sobre educación, evaluación y práctica docente a la luz del вм, dado que, a partir de los preceptos teóricos de Marx y Engels (2014), considero esta entidad como parte representativa de las potencias dominantes de la época, lo cual explica su rol predominante en la gestación y diseminación de las políticas educacionales y evaluativas como organismo al servicio de los intereses del capital (Remolina, 2017).

\section{Educación, evaluación y práctica docente a la luz de organismos multilaterales}

Para el Banco Mundial (вм) (2016), la educación es fundamental para impulsar el desarrollo, más allá de ser uno de los instrumentos más eficaces en la lucha contra la pobreza y a favor del mejoramiento de la salud; pero también, es indispensable para alcanzar la igualdad de género, la paz y la estabilidad.

A pesar de los avances considerables y sistemáticos en términos de renta y disminución de la pobreza, el potencial educativo aún no se aprovecha de manera efectiva, dados los niveles de aprendizaje excesivamente bajos, según el organismo financiero. Por ello, para poner fin a la pobreza antes de finalizar el año 2030, el вм (2016) considera como objetivo principal entregar a toda la población infantil "una educación de calidad que les ayude a adquirir habilidades necesarias en el mundo del trabajo".

Por tanto, entre otros aspectos, el apoyo de este organismo multilateral a los países en desarrollo gira en torno a: enseñar capacidades básicas; aumentar la eficiencia y la transparencia; superar la gran diferencia entre el desarrollo de competencias, la enseñanza superior y el mercado de trabajo, e incrementar el nuevo mecanismo de financiamiento basado en resultados (вм, 2016).

De tal manera que, entre los temas claves del World Bank (2014) para la economía educacional aparecen dos tópicos de importante consideración: gestión escolar y calidad educacional.

En relación con el primer asunto, el World Bank (2014) define gestión escolar como la descentralización de los grados de autoridad a nivel de escuela. En ese sentido, responsabilidad y toma de decisiones sobre asuntos operativos de la escuela son transferidos para la dirección escolar, el profesorado, las familias, el alumnado y la comunidad en general. 
Entre las actividades susceptibles de transferencia de autoridad están: contratación y dimisión del profesorado y demás funcionarios escolares, desarrollo curricular, supervisión y evaluación del desempeño docente y del aprendizaje estudiantil. Así, según el BM, aumentar la responsabilidad de la dirección escolar, del cuerpo docente, de las familias y del alumnado resulta ser una de las razones principales de la gestión escolar con importante incidencia en la mejora educativa.

Por esto, escuela y profesorado deberán ofrecer cuentas a las familias y a la sociedad por los resultados obtenidos en el marco de los indicadores nacionales, así como de los exámenes y de las evaluaciones del aprendizaje (вм, 1996). Además, se debe tener en cuenta que la vigilancia de la familia sobre el desempeño docente es mayor cuando esta se encarga directamente de costear la educación y así comprometer un pago justificado (Hillman y Jenkner, 2004).

Ahora bien, para el teórico neoliberal Hayek (2006), responsabilidad es un atributo individual que, relacionado con el principio de libertad, objetiva alcanzar mayor eficiencia y eficacia, con lo cual la sociedad esperaría ser remunerada de conformidad con el valor de los recursos y servicios prestados a una élite altamente valorada, en nuestro caso, el profesional docente.

En tal sentido, se entendería (a la vez que asumo) responsabilidad como un instrumento de la gestión escolar, cuyo propósito es mejorar la calidad educacional mediante lógicas de mayor eficiencia y eficacia. Así, la calidad educativa está vinculada a los conocimientos y capacidades cognitivas del alumnado (World Bank, 2014). Es por esto que para el Bм resulta necesario implementar evaluaciones rigurosas para documentar las relaciones causales entre reformas educacionales y resultados de aprendizaje.

Sobre esta misma línea de argumentación, el вм considera que el trabajo docente está relacionado directamente con la calidad de la educación. En un estudio financiado por tal entidad, con la participación de más de 15000 docentes de siete países de América Latina y del Caribe, Bruns y Luque (2014) extrajeron evidencias de evaluación y de prácticas educacionales recientes en torno de las reformas de políticas docentes.

Entre las principales conclusiones, los autores consideraron que formar profesoras y profesores de alta calidad requiere selección, desarrollo y motivación personal-profesional. Por esa razón, una estructura salarial vinculada a la evaluación del desempeño debe generar incentivos necesarios para docentes en ejercicio y, en la educación básica, hacer más atractiva la docencia para profesionales de otros sectores académicos.

En resumen, según el BM, la calidad educacional está relacionada directamente con los resultados en pruebas externas (conocimientos, capacidades cognitivas). Su mejora es posible mediante la gestión escolar y su 
dispositivo de responsabilidad que, basado sobre lógicas de eficiencia y eficacia, se articula al trabajo docente por intermedio de la supervisión del desempeño, generando incentivos salariales y motivacionales.

\section{Condiciones laborales en el ámbito de las políticas de evaluación externa}

Al entender que las políticas educacionales implementadas tanto en Colombia como en Brasil se articulan en torno al uso de indicadores de calidad, el impulso de lógicas de gestión escolar, responsabilidad y pago por desempeño, las cuales tienen en el BM uno de sus principales órganos de gestación y difusión (Remolina, 2017), en esta sección se analizó críticamente la percepción docente en torno a estos conceptos.

Por tanto, se dio inicio a la discusión aludiendo el tema de los incentivos salariales y motivacionales, aclarando que tal punto no se consideró en fase de diseño de las entrevistas; sin embargo, fue un asunto que cobró relevancia durante el desarrollo de estas.

En Colombia, dos sujetos entrevistados se refirieron al salario, mientras que en Brasil cinco docentes hicieron menciones en tal sentido. Así, la inconformidad salarial fue relacionada directamente con las pruebas de evaluación externa, tal como refiere una de las profesoras colombianas:

[...] la presión que se está haciendo de obtener puntajes excelentes, [...] más con [docentes] recién nombrados. [Este profesorado] es evaluado anualmente, [...] tiene que buscar un resultado. Entonces, ¿qué pasa con estas personas? [Las directivas escolares] dicen: "Bueno, a usted le dejamos undécimo grado, matemáticas, usted tiene que elevar la calidad". [...] Entonces, pueda ser que eso [...] traiga beneficios para [el alumnado], pero no porque el Gobierno lo incentive, o sea, en el sentido de que "venga le doy unas horas extras, venga le mejoro la infraestructura al colegio, venga le damos juegos didácticos, computadores", no; es porque [el profesorado] en afán de que su calificación no baje, de tener garantizado su salario, entonces, él dedica [parte] de su tiempo, de su economía a traer recursos; claro, eso va a redundar en que el [alumnado] va a obtener un conocimiento mejor; pero, entonces, también es [a] costo de [la población trabajadora], del [profesorado]. (Profesora de Español Escuela Normal Superior, entrevista personal, 19 de agosto de 2015).

Para uno de los profesores brasileños, el dinero invertido en la preparación e implementación de las evaluaciones externas es un derroche de recursos que bien podrían ser utilizados para mejorar las condiciones salariales del docente. 
Ellos [los gobiernos] gastan millones, para no hablar de billones, con evaluaciones externas, montan toda una estructura gigantesca de profesores, de técnicos, [...] para poder hacer ese tipo de evaluaciones; [...] acaban no resolviendo el problema, porque el problema está allá en el profesor que está siendo mal pago, [...] el salario no da para que él tenga una vida digna. (Profesor de Portugués Escola Municipal Mario Godoy, entrevista personal, 29 de mayo de 2015, traducción propia).

Al analizar estas afirmaciones a la luz de las políticas implementadas por países con altos desempeños, según el estudio de Bruns y Luque (2014), financiado por el BM, hay una clara contradicción entre lo sugerido y lo real evidenciado. No se percibe que la docencia, en sus niveles básico y medio, sea una profesión atractiva para el personal docente.

Además, en el caso de Minas Gerais, los bajos rendimientos salariales del profesorado contrastan con el de otros profesionales de igual nivel de formación (Alves y De Rezende Pinto, 2011), otra contradicción que pudo constatarse en la siguiente afirmación de uno de sus docentes:

[¿Qué tipo de emociones y sentimientos generan los resultados de las pruebas externas?] entre estos el sentimiento ¿de qué puedo hacer con tanta precariedad que me colocan? Con un salario tan bajo como el que tenemos, [...] en el caso de Minas Gerais, [...] el educador en general de la enseñanza media, él es el profesional universitario más mal pago de Brasil. No hay otro profesional universitario que gane tan mal como nosotros. [...] Es precario nuestro salario [...]. (Profesor de Filosofía Escola Estadual Bueno Brandão, entrevista personal, 21 de mayo del 2015, traducción propia).

Lo expresado es contrario a lo recomendado por Bruns y Luque (2014, p. 43), quienes sugieren "que las recompensas financieras por enseñar deben alcanzar un nivel de paridad con otras profesiones para atraer [al personal más talentoso]".

En cuanto a la idea de responsabilidad, fueron aludidas expresiones de culpa y temor. Así se manifestaron diez docentes colombianos y la totalidad del profesorado brasileño. A continuación, apartes más destacados de dichas manifestaciones.

[...] entonces, [las evaluaciones externas] contribuyen a que nos sintamos como aterrorizados [...] cuando nos hablan de la prueba [...] Pero yo creo que todo apunta hacia el [profesorado], [...] entonces, uno dice, señalan [al docente] como [...] responsable pero no se acuerdan de que hay un núcleo familiar [...]. Por tanto, ¿cuál es el papel de [la familia]? [...] En este momento todo apunta hacia el [profesorado] [...]. (Profesora de Biología Colegio Facundo Navas Mantilla, entrevista personal, 9 de julio de 2015). 
De insatisfacción, de frustración, a veces de incompetencia, de no realización. Yo hablo por mí, yo hago mi trabajo con dedicación, con cariño, con amor, yo intento conseguir lo máximo que puedo de mi clientela y muchas veces no lo consigo; y cuando viene el resultado negativo, porque yo ya pasé por intervención, ya dos veces, tanto en la escuela del Estado como en la escuela municipal, yo quedo bastante frustrada, es una sensación [temblor de voz] muy desagradable de que no estamos realizando bien nuestro trabajo [...]. (Profesora de Portugués Escola Municipal Mario Godoy, entrevista personal, 29 de mayo de 2015, traducción propia).

Así, en ambas realidades, el cotidiano escolar aparece permeado por diversos sentimientos e inquietudes en torno al trabajo educacional. Por tanto, es posible que las representaciones y las ideologías se construyan en la cotidianidad por medio de la praxis social (Kosík, 1995; Lefebvre, 2006), el análisis crítico de las emociones y sensaciones de ese cotidiano podrían revelar algunas manifestaciones ideológicas. Así como el conocimiento de tal cotidianidad, impregnada de emociones y sensaciones, comprendería a su vez una crítica ideológica (Kosík, 1995; Lefebvre, 1972).

Terror, frustración y temor fueron emociones expresadas por el profesorado de ambos países y, como tal, son atributos esenciales de la sociedad terrorista (Lefebvre, 1972). Esta última, según el autor, se fundamenta en la persuasión (ideología) y la coacción (leyes, normas, decretos), pero utiliza también medios sofisticados, aparentemente inofensivos como la autorrepresión, a tal punto que cada individuo llega a ser terrorista de sí mismo, ejerciendo un poder, así sea momentáneo.

De tal manera, continúa criticando el autor, esta autorrepresión se instala en la cotidianidad organizada y hace inútil la represión por cuanto surge como expresión de libertad debido a su aparente carácter espontáneo. En consecuencia, las contradicciones son suavizadas, incluso eliminadas.

En tal sentido, considero que las evaluaciones externas aparecen como formas de terror, propias de una sociedad sobrerrepresiva fundada en la amenaza de lo escrito. Legalmente se establecen en el ámbito escolar y allí se muestran como una práctica netamente racional y organizacional.

También, surgen como mecanismo sofisticado de coacción, ya que sus resultados se instalan en la conciencia docente a modo de autorrepresión. Esto resulta evidente cuando en el discurso del profesorado entrevistado aparecen autocuestionamientos de tipo "¿qué hago yo?", "¿qué me hace falta hacer?", "como si fuésemos un poco incompetentes"; coacciones autoimpuestas, cuyo relato llega incluso a quebrar la voz, como se evidenció en las declaraciones de una profesora brasileña. 
Como resultado, el docente parece tornarse en terrorista de sí mismo al incorporar/representar el poder del Estado en la escuela. De tal modo, parafraseando a Lefebvre (2006), la cotidianidad escolar representa una organización y una disciplina de la ausencia, donde lo político y sus representaciones parecen ser la única presencia, siendo apenas una simulación, una ausencia suprema.

Ahora, dado que las formas ideológicas unen la intimidación a la fuerza persuasiva (Lefebvre, 1972), me atrevo a indicar que en el discurso del profesorado las expresiones intimidatorias serían el camuflaje de algunas manifestaciones ideológicas, y viceversa; es decir, las ideologías como disimuladoras de la coacción. Así, relacionado con los resultados escolares, el sentimiento de culpa resultaría siendo una forma de autorrepresión.

Se infiere, entonces, que existe una responsabilidad culposa dirigida de fuera de la conciencia hacia el interior de los sujetos docentes. Tal forma de autocensura se interioriza tomando como eje los resultados en las pruebas externas, los cuales, a su vez, están vinculados a la idea cuantificable de calidad educativa. Además, si la responsabilidad está vinculada al recurso instrumental de la gestión escolar, puede afirmarse que sus funciones de control se hacen efectivas mediante autorrepresión.

Al final, responsabilidad resulta siendo una racionalidad técnico-instrumental de una sociedad sobrerrepresiva, que bajo la égida del neoliberalismo y dada su adhesión a las lógicas de gestión, constituiría una manifestación ideológica a la cual aquí se denomina ideología de la gestiocracia. Forma fenoménica que actuaría al mismo tiempo en dos sentidos: induciendo formas de intimidación y asociando autorrepresión con rendimiento escolar.

Así, en el presente trabajo de investigación, propongo el concepto ideología gestiocrática, manifestación fenoménica que a pesar de anunciar en su discurso el deseo del ejercicio de la gestión democrática, en realidad, termina promoviendo una fuerte reproducción alienada de la gestión bajo los dictámenes de la racionalidad técnico-instrumental. Esta, en última instancia, fundamenta la lógica empresarial basada en los criterios cuantitativos de la eficiencia y la eficacia.

En tal contexto, teniendo en cuenta que la cuantificación de lo cualitativo es una de las representaciones sobre las cuales está fundado el capitalismo (Lefebvre, 2006), la calidad educativa se reduce a una representación numérica que permite homogeneizar y reducir el problema educacional a una expresión de fácil observación, manipulación y transferencia.

Por tanto, la gestiogracia resulta ser una estrategia consciente, en cuanto ideológica, por medio de la cual las contradicciones socioeconómicas son excluidas del ámbito escolar al momento de someter la compleja realidad 
educacional a la mera cuantificación de sus resultados en beneficio y concordancia del actual sistema de producción y de consumo. Así, es posible explicar la idea de una educación globalizada, obsesionada con la obtención y mejora de los denominados índices de calidad.

A su vez, la preocupación fue otro de los elementos a destacar. Relacionado con las pruebas externas, aparece como un estado anímico al cual hicieron alusión docentes de ambos países. Por ejemplo, para uno de los profesores entrevistados en Colombia, "en los directivos [las evaluaciones externas] siempre generan preocupación porque [...] en su gran mayoría hay de pronto respeto hacia las pruebas" (profesor de Filosofía, Colegio Facundo Navas Mantilla, entrevista personal, 9 de julio de 2015).

En el caso de Brasil, existe preocupación ante la posibilidad de una intervención pedagógica por parte del personal de la Secretaría de Educación: "[...] cuando el promedio cae quedamos preocupados porque sabemos que vamos a tener intervención" (profesor de Biología, Escola Estadual Lourdes Carvalho, entrevista personal, 10 de junio de 2015, traducción propia).

Este sentimiento es otro de los atributos de la llamada sociedad terrorista de Lefebvre (1972), dado que se utiliza la persuasión junto a la coacción (ideología de la gestiocracia). Pero, también, puede ser concebido como rasgo característico del proceso de fetichización de las relaciones escolares, tomando en consideración los análisis críticos de Kosík (1995) y Popkewitz (1992).

Por un lado, Kosík (1995) aduce que la preocupación es anticipación; ella desprecia el presente y se introduce en el futuro que aún no existe. La dimensión temporal y el existir del individuo se revelan en la preocupación como futuro y temporalidad. Ambos fetichizados. Así, según este pensador crítico, expresiones como "vivir el futuro" o "anticipar" significan una negación de la vida porque el sujeto como preocupación no vive el presente, niega aquello que existe y anticipa lo inexistente, reduciendo su vida a la nulidad, a la inautenticidad.

Por otra parte, Popkewitz (1992) considera la evaluación como un asunto sobre el pasado. Epistemológicamente, según el profesor estadounidense, las evaluaciones comprenden interpretaciones de lo que aconteció, pues no permiten proveer un plano directo del presente o del futuro.

De esto se infiere que, al actuar en función de la preocupación generada por las evaluaciones externas, el profesorado y la escuela en general estarían negando aquello que existe (la realidad escolar), anticipando lo inexistente y operando con aquello que dejó de existir (los resultados de las evaluaciones externas). Como resultado, la vida escolar es reducida a la nulidad y a la inautenticidad. 
Ahora, es posible afirmar que la preocupación y su temporalidad son aspectos derivados y reificados de una praxis evaluativa fetichizada, dado que los individuos, en general, y el profesorado, en particular, son obligados a negar el tiempo presente para situarse, de manera alternada, en aquello que no existe y en aquello que dejó de existir, siendo forzados a menospreciar la realidad escolar para reducirla a la fracción temporal de la resolución de un examen.

En síntesis, la figura 1 presenta la discusión aquí planteada. El trabajo docente aparece relacionado con la ideología de la gestiocracia mediante su dispositivo de responsabilidad, cuya influencia sobre las condiciones laborales se materializa con sentimientos de culpa, terror y frustración. Asimismo, el pago por desempeño es mediador entre trabajo docente y calidad educativa, dado que los incentivos salariales tienden a regular la labor del profesorado en función de esta última, y esta, a su vez, es definida en términos de indicadores cuantitativos dentro de la ideología gestiocrática. En razón a esto último, los indicadores se presentan como mediaciones entre calidad educativa y gestiocracia, tal como puede observarse en la misma figura. También, puede apreciarse que las evaluaciones externas son el centro relacional entre trabajo docente, calidad educativa y gestiocracia. Esto en virtud de que evaluación y calidad están vinculadas directamente, al mismo tiempo que la práctica docente se orienta a la obtención de resultados en tales tipos de exámenes bajo la lógica gestiocrática de la eficiencia y la eficacia.

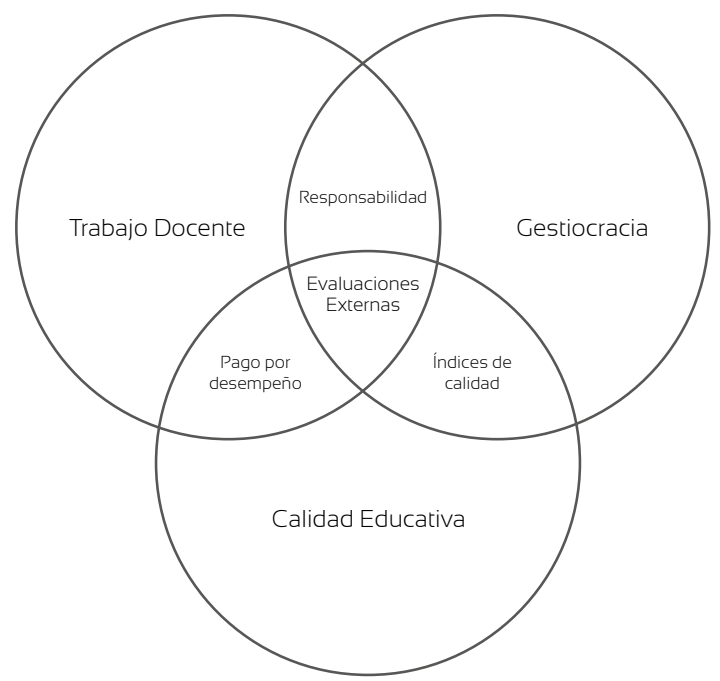

Figura 1

Diagrama relacional entre trabajo docente, gestiocracia y calidad educativa 


\section{Consideraciones finales}

El presente trabajo tuvo por objetivo investigar y analizar críticamente de qué manera las políticas de evaluación externa implementadas en Colombia y Brasil influyen en las condiciones laborales del profesorado de ambos países. A partir de este interés, nos referimos a las percepciones docentes sobre la materialización de estas políticas en ambas realidades, adoptando la perspectiva de los estudios históricos comparados dentro de la matriz teórico-metodológica del materialismo histórico-dialéctico. En ese sentido, se realizaron entrevistas semidirigidas con profesoras y profesores que actuaban en diferentes áreas de seis escuelas públicas de Colombia y Brasil.

Así, la categoría trabajo docente, entre otras, emergió de la totalidad concreta construida, instituyéndose en tema central del presente artículo.

Entre los resultados más destacados pudo evidenciarse que organismos internacionales al servicio del capital, como el Banco Mundial (BM), al mediar en la configuración de las políticas educacionales colombianas y brasileñas, influyen en las condiciones laborales del profesorado. Tal influencia se circunscribe al ámbito ideológico generado en torno de dos temas claves: calidad educativa y gestión escolar.

El primero de estos se relaciona directamente con los resultados en pruebas externas. Así, el mejoramiento de la calidad educativa se considera posible mediante la gestión escolar y su dispositivo de responsabilidad que, sobre lógicas de mayor eficiencia y eficacia, se articula al trabajo docente por medio de la vigilancia y del control del desempeño.

De tal manera, con relación a la carrera magisterial, el вм considera necesario implementar una estructura salarial que, vinculada a la evaluación del desempeño docente, genere incentivos no solo económicos sino también motivacionales. Con estos se pretende hacer de la docencia, en sus niveles básico y medio, una profesión atractiva para los profesionales más sobresalientes de los diversos ámbitos académicos y productivos.

Sin embargo, la vivencia de los profesionales docentes en ambos países contradice los postulados educacionales pregonados por el вм que, materializados en políticas evaluativas, terminan influenciando las condiciones materiales (remuneración salarial) e inmateriales (representaciones e ideologías) del profesorado.

Por un lado, en ambas realidades, mediante el análisis del discurso, pudo evidenciarse que no existen incentivos salariales o motivacionales a favor del docente. Por el contrario. Los comentarios expresados mostraron un fuerte inconformismo frente a la política que regula la profesión educacional en ambos sistemas escolares. Por esto, no resulta claro que la 
docencia en la educación básica y media pueda ser una carrera profesional atractiva para el personal altamente calificado de otros sectores académicos y productivos de la sociedad colombiana y brasileña.

Además, es obvio que la falta de incentivos salariales y motivacionales tiene profundos impactos sobre las condiciones laborales del profesorado, principalmente, cuando a esta contradicción se añade la carga de responsabilidad por los resultados en las pruebas de evaluación externa. Al final, no solo se trataría de consecuencias profesionales, sino también de la vulneración del derecho a la vida digna de las trabajadoras y los trabajadores docentes.

Por otro lado, dos afirmaciones de Lefebvre (2006) fueron fundamentales para el análisis ideológico de las políticas de evaluación externa de ambos sistemas escolares. Primero, reconocer que las representaciones son el camino intermedio entre instinto e ideología y, segundo, el hecho de que la cuantificación de lo cualitativo sea la representación basilar del actual modelo de producción capitalista.

Se puede afirmar que la ideología gestiocrática, manifestada en el discurso del profesorado entrevistado de ambos países, promueve la reproducción alienada de la gestión bajo los dictámenes de la lógica técnico-instrumental de la eficiencia y la eficacia empresarial, utilizando para ello el dilema oportuno de la participación democrática.

Tal manifestación ideológica disimula las contradicciones socioeconómicas de los sistemas educacionales, sometiendo la compleja realidad escolar a la mera cuantificación de sus resultados, es decir, convirtiendo, al final de cuentas, lo cualitativo en cuantitativo.

Así, la responsabilidad se ubica como mecanismo de intermediación entre la ideología gestiocrática y el trabajo docente. Tal forma de coacción encuentra en las evaluaciones externas su principal instrumento de autorrepresión mediante el cual el profesorado colombiano y brasileño es controlado dentro de la lógica de la sociedad terrorista que plantea Lefebvre (2006).

En otras palabras, las evaluaciones externas aparecen como formas sofisticadas de represión y autorrepresión. Otra estrategia consciente de la gestiocracia, cuyo objetivo es suprimir las contradicciones laborales del profesorado, de tal manera que el docente sea único responsable de sus propias condiciones de trabajo y único culpable de la crisis educativa.

Ahora bien, así como la culpa es muestra clara de la intermediación ejercida por la responsabilidad, la preocupación es otro elemento que emerge de esta mediación entre trabajo docente e ideología gestriocrática. Además de ser un atributo de la denominada sociedad terrorista, también revela el carácter fetichizado de las evaluaciones externas. Razón por 
la cual este tipo de pruebas colocan al profesorado frente a su realidad educacional en una relación de negación, donde la fracción temporal de la resolución de un examen es el único presente. De tal suerte, la vida escolar se reduce a la nulidad y a la inautenticidad.

Por otra parte, dado que la cuantificación de lo cualitativo es la representación fundamental del capitalismo (Lefebvre, 2006), de igual manera podría afirmarse que una educación basada en indicadores de calidad es representación basilar de una educación capitalista que no solamente está orientada a reproducir ideológicamente un sistema de producción y consumo, sino también, a contribuir con un proceso paulatino de precarización del trabajo docente.

Finalmente, vale la pena abrir el debate sobre la labor educativa y los fines educacionales. De modo que, si es posible reconocer el potencial transformador del docente de la educación básica y media a nivel individual y social, dado su trabajo intelectual con la población más vulnerable de la sociedad en el contexto de la escuela pública, entonces, ¿será probable que este tipo de políticas evaluativas pretendan contener tal posibilidad de cambio precarizando las condiciones laborales del profesorado? Por tanto, en el nuevo escenario planteado por las políticas de evaluación externa, resulta necesario e inaplazable abrir el debate en torno a los verdaderos fines de la educación y de la práctica evaluadora.

\section{Referencias}

Alves, T. y De Rezende Pinto, J.M. (2011). Remuneração e características do trabalho docente no Brasil. Cadernos de Pesquisa, 41(143), 606639; Recuperado de http://publicacoes.fcc.org.br/ojs/index.php/cp/ article/view/105/113

Atlas.ti (version 1.0.46 (208)). [Software]. (2015). Recuperado de https:// atlasti.com/product/mac-os-edition/

Banco Mundial (вм) (1996). Prioridades y estrategias para la educación. Washington, D.C.: Banco Internacional de Reconstrucción y Fomento/Banco Mundial. Recuperado de http://documentos.bancomundial.org/curated/es/715681468329483128/pdf/14948010spanish. pdf

Banco Mundial (вм) (2016). Educación. Panorama general. Recuperado de http://www.bancomundial.org/es/topic/education/overview\#1

Bruns, B. y Luque, J. (2014). Docentes excelentes. Resumen. Washington, D.C.: Banco Mundial. Recuperado de https://openknowledge.worldbank.org/bitstream/handle/10986/20488/Spanish-excellent-teachers-report.pdf? sequence $=5$ 
Ciavatta, M. (2009). Estudos comparados. Trab. Educ. Saúde., 7(suplemento), 129-151. Recuperado de http://www.scielo.br/pdf/tes/ v7s1/07.pdf

De Freitas, L.C. (2012). Os reformadores empresariais da educação: da desmoralização do magistério à destruição do sistema público de educação. Educ. Soc., 33(119), 379-404.

Dussel, E. (2012). A produção teórica de Marx. 11a. ed. São Paulo: Expressão Popular.

Franco, M.C. (2000). Quando nós somos o outro. Educ. Soc., 21(72), 197-230; Recuperado de http://www.scielo.br/pdf/es/v21n72/4200. pdf

Hayek, F.A. (2006). Los fundamentos de la libertad. Clásicos de la Libertad. 71a. ed. Madrid: Unión Editorial.

Hillman, A.L. y Jenkner, E. (2004). La educación de los niños en los países pobres. Temas de Economía 33. Washington, D.C. Recuperado de https://www.imf.org/external/pubs/ft/issues/issues33/esl/issue33s.pdf

Instituto Colombiano para la Evaluación de la Educación (ICFES) (2016). ISCE: Guía metodológica. Boletín Saber en Breve, (5), 1-4.

Kosík, K. (1995). Dialética do concreto. 21a. ed. Río de Janeiro: Paz e Terra.

Lefebvre, H. (1958). Critique de la vie quotidienne. 21a. ed. París: L'Arche Éditeur.

Lefebvre, H. (1972). La vida cotidiana en el mundo moderno. Humanidades. Madrid: Alianza Editorial.

Lefebvre, H. (1975). Lógica formal. Lógica dialéctica. Río de Janeiro: Civilização Brasileira.

Lefebvre, H. (2006). La presencia y la ausencia: contribución a la teoría de las representaciones. México D.F.: Fondo de Cultura Económica.

Malaver, C. (2015). Llegó la hora de que colegios pasen al tablero cada año. Eltiempo.com. Recuperado de http://www.eltiempo.com/bogota/nuevo-modelo-de-educacion-en-colombia/15399375; [Fecha de consulta: marzo 16 de 2015]

Marx, K. y Engels, F. (2014). La ideología alemana. Serie Clásicos. Madrid, España: Ediciones Akal.

Popkewitz, T.S. (1992). A Political/Sociological Critique of Teacher Education Reforms. En Focus on Evaluation and Measurement (pp. 287-314). Tomos 1-2 de Information Analyses - Viewpoints; National Research Symposium on Limited English Proficient Student Issues. Washington, D.C.: EDRS. Recuperado de http://files.eric.ed.gov/fulltext/ED349818. pdf

Ravitch, D. (2011). Vida e morte do grande sistema escolar americano: Como os Testes Padronizados e o Modelo de Mercado Ameaçam a Educação. Porto Alegre: Sulina. 
Remolina, J.F. (2012). La evaluación en el contexto escolar de Francia y Portugal. RLEE; XLII(2), 95-117. Recuperado de http://cee.edu.mx/

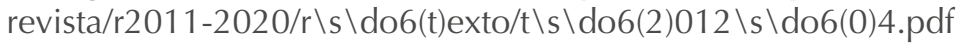

Remolina, J.F. (2017). Crítica das políticas de avaliação externa na Colômbia e Brasil no contexto da sociedade capitalista. (Tesis Doctoral). Programa de Pós-Graduação em Educação da Faculdade de Educação da Universidade Federal de Uberlândia; Uberlândia, MG.

Sanchez, C.M. (2015). "Nuestros hijos pueden ser los más educados de Latinoamérica": Santos. Eltiempo.com. Recuperado de http://www. eltiempo.com/bogota/nuestros-hijos-pueden-ser-los-mas-educados-de-latinoamerica-santos/15460955; [Fecha de consulta: marzo 25 de 2015]

Sistema Informativo del Gobierno (sIG) (2014). Colombia debe trazarse hoy una meta: ser la nación más educada de América Latina en el año 2025. Recuperado de http://wsp.presidencia.gov.co/Prensa/2014/Febrero/Paginas/20140212_05-Colombia-debe-trazarse-hoy-una-meta-ser-la-nacion-mas-educada-de-America-Latina-en-el-2025.aspx; [Fecha de consulta: abril 19 de 2015]

World Bank (2014). Economics of Education. Brief. Recuperado de http:// www.worldbank.org/en/topic/education/brief/economics-of-education 